Gladys Camacho Cepeda*, Andrés Gomez-Lobo R.**

\title{
Las Normas Ambientales, un desafío pendiente para la coordinación administrativa.
}

* Profesora de Derecho Administation, Facultad de Derecho, Universidad de Chile

**Doctor en Medio Ambiente, Consultor.

\section{Resumen}

En este artículo se discute la tramitación que han seguido las normas ambientales y el cumplimiento o no del procedimiento administrativo exigido por el legislador para su aprobación. En una materia como la ambiental, tan necesitada de un actuar coordinado, la Administración aún no asimila los principios básicos sobre los que se sustenta este nuevo ordenamiento, no obstante las claras directrices impartidas por el legislador. La observancia de un requisito esencial como es el procedimiento, en este caso administrativo, incide en la validez de las normas aprobadas, de ahí que es de especial relevancia el seguimiento de la actuación administrativa con el objeto de establecer su actuar concordante con el principio de legalidad, y contrastar la validez de su actuación. Este ejercicio de seguimiento dio origen al presente trabajo, $y$ en las siguientes líneas se expone el resultado de lo encontrado.

SUMARIO: 1.Introducción: La incidencia de la aplicación de la Ley de Bases del Medio Ambiente en las competencias de los servicios públicos. 2. Régimen jurídico de las Normas de Calidad Ambiental y las Normas de Emisión. 3. Aplicación práctica del procedimiento de aprobación de normas ambientales. 4. Conclusiones.

\section{Introducción: La incidencia de la aplicación de la Ley de Bases} del Medio Ambiente en las competencias de los servicios públicos.

La Ley de Bases del Medio Ambiente N $^{\circ} 19.300$ (en adelante sólo L.B.M.A.) traía un esquema administrativo nuevo modernizador, que debía ensayarse mediante el establecimiento de una "ventanilla única" que facilitase a los administrados su relación 
con los numerosos servicios públicos, mediante la unificación de trámites en la obtención de permisos.

En la tramitación de la Ley, los legisladores parlamentarios, hicieron varios alcances orientados a prevenir la entonces existente descoordinación institucional y la dispersión de atribuciones legales en lo relativo a la gestión ambiental. A la par con este objetivo, se fue acuñando el concepto de "ventanilla única", que consistiría en un procedimiento de carácter administrativo en el que las autorizaciones y los diversos permisos sectoriales relativos a los proyectos productivos que se pretendieran llevar a cabo se resolverían, en lo posible, en una sola instancia o ante una misma autoridad.

La función de la CONAMA para los legisladores se debía remitir a una función de coordinación muy intensa que no debía desconocer las competencias ambientales de los distintos ministerios y servicios públicos. Dicha función debía realizarse en dos direcciones:

$1^{\circ}$ Involucrándolos en los temas ambientales que, por sus respectivas esferas de competencia, les corresponde conocer; $y$

$2^{\circ}$ Generando una capacidad de coordinación al interior del Ejecutivo que permita evitar la duplicación de esfuerzos.

En concordancia con la idea maestra de establecer la ventanilla única, el legislador también estableció un sistema de coordinación que no pretendía radicar el tema ambiental en una sola institución, porque ello implicaría una reestructuración del aparato público a un costo injustificado, y desperdiciar la capacidad institucional instalada, sino más bien aprovechar la capacidad de coordinación de la CONAMA para liderar la formulación de la regulación ambiental básica que debía empezar a generarse y aprobarse a través de normas de calidad ambiental y de emisión. Así se daría cumplimiento a uno de los objetivos que persegúa la Ley de Bases del Medio Ambiente, cual era ser el pilar central sobre el cual se erigiría y sistematizaría el ordenamiento ambiental. En esta materia, si bien el legislador optó por no desconocer la legislación que le precedía, y de este modo, escogió respetar las normas con incidencia ambiental vigentes al momento de su promulgación, también buscaba a partir de esta Ley dar coherencia a las normas ambientales.

Lo señalado se expresó en el artículo $1^{\circ}$ de la L.B.M.A. ${ }^{1}$ el cual debe interpretarse a la luz de lo expresado por el Presidente de la República en su mensaje con el que remite al Congreso el proyecto de ley en comento, en el que da cuenta que ${ }^{2}$ :

1 Este artículo preceptúa lo siguiente: "El derecho a vivir en un medio ambiente libre de contaminación, la protección del medio ambiente, la preservación de la naturaleza y la conservación del patrimonio ambiental se regularán por las disposiciones de esta ly, sin perjuicio de lo que otras normas legales establezcan sobre la materia".

2 Ver Mensaje No387-324/1992 de 14 de septiembre de 1992, con el que el Presidente de la República, D. Patricio Aylwin Azocar, envió al Congreso Nacional el proyecro de Ley de Bases del Medio Ambiente. 
$1^{0}$ "... La legislación ambiental vigente ha sido dictada en forma sectorial y compartimentalizada, sin una visión global e integradora. Por lo mismo, no se ha hecho cargo de las relaciones de interacción e interdependencia que se dan entre los diferentes componentes del ambiente. También ha carecido de principios generales y objetivos predefinidos a los cuales responder dentro de una politica ambiental."

$2^{\circ}$ "... si hay un tema en el cual las competencias están distribuidas a lo ancho de todo el sector público, es en el tema ambiental. Prácticamente no hay ministerio o servicio que no tenga radicadas, en alguna medida, competencias relacionadas con la problemática ambiental, entendiendo por ésta las variables de manejo de los recursos naturales y de enfrentamiento de los fenómenos de contaminación"; y

$3^{\circ}$ Frente a las dos situaciones descritas un elemento de gestión ambiental clave es la legislación, de la cual esta L.B.M.A. deberá constituirse, sin duda, en "uno de los principales instrumentos para alcanzar los objetivos perseguidos por la politica ambiental. En efecto, los diferentes titulos, párrafos y disposiciones de la ley responden a una serie de principios generales básicos que conforman la politica ambiental de este gobierno, sin cuya existencia sus disposiciones aparecerian vacuas y carentes de un sentido y objetivos especificos claros. Será éste, pues, el primer cuerpo normativo que recoja en forma integrada y global los principales temas ambientales, y los principios que, a nuestro juicio, deberán ser sustento y fundamento de cuerpos legales posteriores."

En este contexto se puede afirmar que el artículo $1^{\circ}$ sólo tiene una interpretación válida y coherente con el ordenamiento ambiental que se empieza a erigir desde la promulgación de la L.B.M.A., este es que la frase "sin perjuicio de lo que otras normas legales establezcan sobre la materia" se debe entender referida a las disposiciones previas a dicha ley. Las cuales, incluso en su aplicación, deberán armonizarse con los nuevos instrumentos que contempla la ley, esto último, por exclusivamente efecto de la capacidad innovadora que tiene toda ley posterior sobre los cuerpos normativos de igual o inferior jerarquía.

En este sentido, si bien no se desconocen las competencias ambientales que tienen repartidas los diversos servicios públicos, éstas deberán ejercerse a partir de la promulgación de la L.B.M.A. de un modo coordinado, función cuya responsabilidad queda a cargo de la nueva institucionalidad ambiental creada por la ley, esto es, la Comisión Nacional de Medio Ambiente (CONAMA). ${ }^{3}$ Así, el artículo 70 de la L.B.M.A. le confiere a la CONAMA, entre otras, las siguientes funciones:

3 De acuerdo al Mensaje Presidencial citado en nota anterior: "... la institucionalidad ambiental debe desarrollarse sobre dos bases. Por una parte, reconocer las competencias ambientales de los distintos ministerios y servicios, involucrándolos en los temas ambientales en que, por sus respectivas esferas de competencia, les corresponde conocer. Por otra, generando una capacidad de coordinación al interior del Poder Ejecutivo." 
“a) Proponer al Presidente de la República las políticas ambientales del gobierno;

b) Informar periódicamente al Presidente de la República sobre el cumplimiento y aplicación de la legislación vigente en materia ambiental;

c) Actuar como órgano de consulta, análisis, comunicación y coordinación en materias relacionadas con el medio ambiente;

e) Administrar el sistema de evaluación de impacto ambiental a nivel nacional, coordinar el proceso de generación de las normas de calidad ambiental y determinar los programas para su cumplimiento".

Interesa destacar entre las funciones, que la nueva institucionalidad ambiental tiene para los efectos del examen que aquí se realiza, la de ser una entidad coordinadora de todas las materias relacionadas con el medio ambiente y especialmente, en lo que se refiere a la generación de las normas de calidad ambiental que la L.B.M.A. regula.

\section{Régimen Jurídico de las Normas de Calidad Ambiental y de las Normas de Emisión.}

Las Normas de Calidad Ambiental (en adelante N.C.A.) son un instrumento básico para conseguir un desarrollo sustentable, de acuerdo a como las ha diseñado la L.B.M.A.. Ellas "son un reflejo de lo que la ciudad está dispuesta a sacrificar con tal de tener menores niveles de riesgo para la salud." Su regulación se contiene en el párrafo $4^{\circ}$ de los Instrumentos de Gestión Ambiental contenida en la L.B.M.A.

Existen al respecto dos tipos de N.C.A., según su objetivo esté referido a proteger la salud de la población o la preservación de la naturaleza. Estas son respectivamente las normas primarias de calidad ambiental y las normas secundarias de calidad ambiental. Su diferencia radica en lo siguiente:

$1^{\circ}$ Las normas primarias de calidad ambiental son aquellas que establecen los valores de las concentraciones y periodos máximos o minimos permisibles de elementos, compuestos, sustancias, derivados quimicos o biológicos, energias, radiaciones, vibraciones, ruidos o combinación de ellos, cuya presencia o carencia en el ambiente pueda constituir un riesgo para la vida o la salud de la población (artículo 2, letra n) de la L.B.M.A.).

Serán de aplicación general en todo el territorio general de la República y definirán los niveles que originan situaciones de emergencia.

Se aprobarán por decreto supremo, firmado por los Ministros de la Secretaria General de la Presidencia y de Salud.

$2^{\circ}$ Las normas secundarias de calidad ambiental son aquellas que establecen los valores de concentraciones y periodos, máximos o minimos permisibles de sustancias, elementos, energía o combinación de ellos, cuya presencia o ca-

4 Ver discurso presidencial citado. 
rencia en el ambiente pueda constituir un riesgo para la protección o la conservación del medio ambiente, o la protección de la naturaleza (artículo 2, letra ñ) de la L.B.M.A.).

Se aprobarán por decreto supremo, firmado por los Ministros de la Secretaría General de la Presidencia y el competente, según la materia de que se trate, y el ámbito territorial de aplicación será dispuesto en el mismo decreto pudiendo ser todo o parte de la República.

La relevancia del establecimiento de una norma de calidad ambiental es que ésta significa la fijación de una meta para la gestión ambiental. Lo que se busca con ellas en las áreas en las que se aplican, es que conlleven mejoramientos de la calidad ambiental por cuanto definirán estándares que se constituirán en las metas de calidad objetivo de la gestión ambiental, y en particular, el objetivo de la política de control de la contaminación. Pero por otro lado, también estas normas constituyen los niveles de riesgo máximos permisibles bajo los cuales no se realizarán esfuerzos de control de emisiones. De ahí su gran significación económica para los agentes productivos y de parámetros de control para las autoridades fiscalizadoras en esta materia.

Por su parte, las Normas de Emisión ${ }^{5}$ establecen la cantidad máxima permitida para un contaminante, medida en el efluente de la fuente emisora. Su ámbito territorial de vigencia es siempre parcial y tendrá que quedar establecido en el Decreto Supremo que la sanciona (art. 40 L.B.M.A.). Son normas de carácter sectorial, por cuanto el sector o Ministerio por el cual se aprueban, dependerá de la materia de la que se trate, lo que no obsta a las facultades de la CONAMA para proponer, facilitar y coordinar la dictación de estas normas acorde a un procedimiento con iguales etapas que las señaladas para las N.C.A. en el artículo 32 de la L.B.M.A..

Los dos tipos o clases de normas de calidad ambiental arriba descritas, de acuerdo al artículo 32 de la L.B.M.A., deberán ser :

1. Aprobadas mediante un procedimiento establecido por un reglamento el que necesariamente debe contener las siguientes etapas: análisis técnico y económico, desarrollo de estudios cientificos, consultas a organismos competentes, públicos y privados, análisis de las observaciones formuladas y una adecuada publicidad. Dicho reglamento establecerá, además, los plazos y formalidades y los criterios para revisar las normas vigentes;

$2^{\circ}$ Revisadas por la CONAMA a lo menos cada cinco años, aplicando el mismo procedimiento que se siguió para su aprobación; $y$

$3^{\circ}$ Coordinadas en su proceso de generación y de determinación de los programas y plazos de cumplimiento, por la CONAMA.

5 La letra o) del articulo $2^{\circ}$ de la L.B.M.A, define como norma de cmisión a aquelia que "establece la cantidad maxima permitida para un contaminante, medida en el fluente de la fuente emisora". 
Por lo que respecta a las normas de emisión, el artículo 40 de la L.B.M.A. establece que su dictación deberá someterse a las mismas etapas señaladas para las N.C.A. en el artículo 32 y en su reglamento, en lo que fueren procedentes, por lo que el esquema básico para su aprobación y revisión es el mismo.

Efectivamente, el reglamento que dispone el procedimiento de aprobación de las normas de calidad ambiental se dictó mediante Decreto Supremo No93/95 del Ministerio Secretaría General de la Presidencia, de 15 de mayo de 1995, el cual esquemáticamente consiste en lo siguiente ${ }^{6}$ :

- Aprobación de un Programa Priorizado de Normas: en el que se establece cuáles son las normas cuya tramitación se llevará a cabo en el año respectivo.

- Proceso de Elaboración del Anteproyecto (150 días). Se inicia con la resolución de! Director Ejecutivo de CONAMA, que ordenará la formación del expediente público, establece el Comité Operativo de la norma, y establece el plazo para la recepción de antecedentes. En este plazo se deberán encargar los estudios técnicos, científicos y los antecedentes necesarios para fundamentar y formular el anteproyecto de la norma. Además, el Director encargará un análisis general del impacto económico y social del anteproyecto de norma.

- Proceso de Consulta del Anteproyecto de Norma (60 días). Se inicia con la aprobación, mediante resolución del anteproyecto, y la publicación de un resumen del anteproyecto en el Diario Oficial y en otro periódico de circulación nacional. Se solicitará la opinión de los Consejos Consultivos Regionales y Nacional, según corresponda, y se recabarán las observaciones y consultas técnicas que formulen por escrito cualquier persona, natural o jurídica.

- Proceso de Elaboración del Proyecto Definitivo de Norma (60 días). A la luz del análisis de las observaciones formuladas, de los antecedentes que obran en el expediente y de los resultados de los estudios, el Comité Operativo formulará el proyecto definitivo (45 días) que será sometido al Consejo Directivo de la CONAMA. El Consejo Directivo, previa discusión y aprobación (15 días), propondrá al Presidente de la República el texto definitivo para su consideración y eventual promulgación.

De este procedimiento regulado para la aprobación de normas de calidad, interesa destacar lo siguiente:

$1^{\circ}$ Es un procedimiento que responde a los principios de objetividad $\mathrm{e}$ imparcialidad de la actuación administrativa, por cuanto busca garantizar que las normas de calidad sean producto de un análisis complejo en el que se tenga en cuenta una evaluación de los impactos económicos y

6 El esquema que se reproduce es el elabotado por la Lnidad de Planes y Normas de la CONAMA y que se encuentra disponible en su página web www.conarna.cl. 
sociales de dichas normas, evaluándose los costos de cumplimiento de los emisores, impactos evitados y riesgos aceptados en salud, asociados a los valores propuestos; $y$

$2^{\circ}$ Se trata de un procedimiento público, con etapas y plazos definidos, orientado a garantizar la participación ciudadana en la definición de los riesgos que la sociedad, en su conjunto, está dispuesta a aceptar en materia ambiental, de forma que se compatibilice la adecuada protección de nuestro medio ambiente con la definición de un marco mínimo indispensable para alcanzar el desarrollo económico.

Ambos aspectos, como seguidamente se verá, han tenido una irregular aplicación práctica.

\section{Aplicación Práctica del Procedimiento de Aprobación de Normas Ambientales.}

A partir de la promulgación de la Ley de Bases del Medio Ambiente, se han producido diversos ejemplos en los que el procedimiento para la dictación de normas ambientales (normas de calidad y normas de emisión) se ha aplicado disímilmente, entre ellos cabe destacar:

a) Decreto Supremo N N $^{\circ} 46 / 1997 /$ Ministerio de Salud (D.O.17 de abril de 1998), que establece norma de emisión de ruidos molestos generados por fuentes fijas, elaborada a partir de la norma de emisión contenida en el Decreto Supremo N $^{\circ} 286 / 1984$ del Ministerio de Salud. La revisión y formulación de esta norma de emisión fue incluida en el Primer Programa Priorizado para la Dictación de Normas Ambientales para 1996/1997. Este caso, en especial, constituye un ejemplo destacable en la práctica, no siempre consecuente de promulgación de normas ambientales, por cuanto una norma sectorial aprobada previamente a la vigencia de la L.B.M.A., una vez que ésta ha entrado en vigencia, y por constatarse que su naturaleza corresponde a lo que la ley de bases califica como norma de emisión, se somete al procedimiento de aprobación de normas ambientales bajo la coordinación de la CONAMA. Con ello, las competencias ambientales sectoriales se ejercen armónicamente y de forma coordinada, siendo esta conducta acorde con el objetivo pretendido por el legislador de bases.

b) El Decreto Supremo No165/1998/Ministerio Secretaría General de la Presidencia. Establece norma de emisión para la regulación del contaminante arsénico, cuya historia es bastante elocuente de la problemática que suscita la aprobación de cualquier N.C.A. Este decreto es una norma de especial importancia, por cuanto regula los límites máximos permisibles a un elemento científicamente comprobado como un 
potente agente carcinógeno. En virtud de lo cual el Presidente Aylwin, poco antes de cesar en su cargo, dictó el Decreto Supremo No477, del Ministerio de Salud, de fecha 28 de enero de 1994 (D.O. 18/04/1994), que estableció la Norma Primaria de Calidad del aire para el elemento químico Arsénico.

No obstante las graves y determinantes consideraciones que se argumentaron para la promulgación del Decreto Supremo No477/1994/Ministerio de Salud ${ }^{7}$ y la urgencia para adoptar en el más breve plazo las medidas para controlar la situación en que se halla el país, en virtud a los aitos valores presentes de este elemento en el ambiente, a los pocos meses de asumir el mando, el Presidente don Eduardo Frei Ruiz-Tagle, mediante Decreto Supremo No1364 del Ministerio de Salud, de fecha 14 de junio de 1994, detoga el Decreto Supremo No477/1994 citado. Para decretar esta derogación, el Presidente invoca la necesidad de seguir el procedimiento dispuesto por la Ley de Bases Generales del Medio Ambiente en especial porque "una norma de tanta importancia como la de la calidad de aire para arsénico" (Cons. 30) debe ser dictada en el marco del procedimiento que considera: "las etapas de análisis técnico y económico, desarrollo de estudios cientificos, consultas a organismos competentes, públicos y privados, y finalmente análisis de las observaciones formuladas y una adecuada publicidad" (Cons. $2^{\circ}$ ). Es de notar que la argumentación sobre la omisión del procedimiento se realiza aun cuando no se había promulgado el Reglamento de Dictación de Normas Ambientales al que remitía la L.B.M.A.

Por esta decisión gubernamental, se reconduce al procedimiento establecido para la aprobación de N.C.A. a la norma de calidad relativa al Arsénico, lo cual constituye un afianzamiento de los instrumentos contenidos en la L.B.M.A. Consiguientemente, mediante Resolución Exenta No109 del Ministerio Secretaría General de la Presiden-

7 El citado decreto se fundamenta en los siguientes considerandos:

"1. Que el adecuado control y prevención de la contaminación atmosférica exige disponer de normas que definan los valores de aquellos contaminantes que perjudican la salud de las personas;

2. Que una norma primaria, está relacionada con la protección de la salud humana y será aplicada a todo el territorio nacional seqún definición doda en el decreto supremo No$^{185}$ de 1992, artículo $3^{\circ}$;

3. Que el arsénico inorgánico es un elemento cancerigeno humano comprobado, clasificado en el grupo I (IARC-1987), EPA y OMS (1998), habiéndose demostrado cientificamente que la exposición a través de la via aćrea produce cáncer broncopulmonar (órgano blanco);

4. Que no existe para los cancerigenos como el arsénico, dosis umbral conocida ni nivel seguro de exposición, siendo su efecto acumulativo en el tiempo;

5. Que estudios nacionales han demostrado mayor riesgo de morir y enfermar en la población que habita en direas geográficas expuestas a arsénico;

6. Que las mediciones de concentración de arsénico en aire, realizadas en algunas regiones del país, muestran que los valores alcanzados exceden los niveles recomendables para la salud de la población;

7. Que es necesario adoptar, oportunamente y en el plazo más breve posible, las medidas destinadas a controlar la situación anterior;

8. Que de este modo se estaría cumpliendo con lo establecido en la Constitución del Estado, al ser consecuente con el desarrollo sustentable, ya que junto con proteger los aspectos económicos y sociales de la nación, se protege la salud de la población." 
cia, de 13 de marzo de 1997 (D.O. 21/03/1997), se da inicio a la elaboración del Anteproyecto de Norma para la Regulación del Contaminante Arsénico emitido al aire. $^{8}$

Este procedimiento de elaboración de la norma de emisión relativa al arsénico, por las características complejas del mismo, tuvo aproximadamente dos ańos de duración y recién culminó con la aprobación del Decreto Supremo No165/1998 del Ministerio Secretaría General de la Presidencia (D.O. 2/06/1999). Es decir, el procedimiento, no obstante la gravedad e importancia de la materia, duró, por las características complejas del mismo, más de dos años en salir a la luz definitivamente. Consiguientemente, el caso aquí referido es una muestra de la importancia del sometimiento al procedimiento establecido, aunque esto signifique dilatar la promulgación de una norma tan importante como la mencionada -casi dos años- y que supuso en su momento la derogación de una norma de calidad.

c) El Decreto Supremo No59/1998/Ministerio Secretaría General de la Presidencia (D.0. 25/05/1998) que establece la Norma de Calidad Primaria para material particulado respirable MP10

Este es un caso de aplicación del procedimiento de dictación de N.C.A. aún más errático que el anteriormente comentado y que, básicamente se puede sintetizar del siguiente modo:

10 Esta es una materia que estuvo regulada anteriormente por el D.S. No 185/1991/Ministerio de Minería; el D.S. No32/1990/Ministerio de Salud, y sus modificaciones, que establecían los valores que definen las situaciones de emergencia; y por la Resolución Exenta No369 de 1998 del Ministerio de Salud.

$2^{\circ}$ La revisión de las normas reguladoras del material particulado respirable MP10 fue aprobada mediante Resolución Exenta No0492, del 25 de julio de 1997, de la Dirección Ejecutiva de la CONAMA, por la que se inicia el procedimiento para la elaboración de la nueva norma de calidad ambiental sobre la materia.

$3^{\circ}$ Luego de haber practicado todo el procedimiento establecido en el Decreto Supremo No 93/1995/Ministerio Secretaría General de la Presidencia (estudios científicos, informes técnicos y otros antecedentes, y la información pública), se culmina con la dictación del D.S. №59/ 1998 del mismo Ministerio.

8 A respecto cabe anoter que, si bien esta norma, inicialmente, se postuló indiscutiblemente como una norma primaria de calidad ambiental, finalmente termina tramitándose como una norma de emisión. Este cambio de! tipo de norma no es meramente adjerivo, sino que tiene trascendental significado en cuanto a la poítica de control y prevención que permite. En virtud de este cambio de naturaleza de la norma, ya no se pone el acento en los valores máximos del arsénico presentes en la atmósfera, y que pueden dañar la salud, sino en los valores máximos que una fuente puede ernitir al aire, lo que termina diluyendo las exigencias que la norma comportaría si se tratara de una norma primaria de calidad ambiental. 
$4^{\circ}$ No obstante que es clara la disposición contenida en la L.B.M.A. del artículo 32 que ordena que las N.C.A. sean revisadas (a lo menos cada 5 ańos), aplicando el mismo procedimiento que se siguió para su aprobación. Mediante Decreto Supremo No45/2001/Ministerio Secretaría General de la Presidencia, se modifica dicha norma so pretexto de introducir "algunos ajustes técnicos", introduciendo aspectos no secundarios para su aplicación, como son la variable del entorno de las estaciones de monitoreo existentes al momento de la fiscalización, y una serie de conceptos importantes como la de efectos crónicos, concentración mensual y anual, entre otros, lo que se realiza sin seguir el procedimiento que la ley exige para su revisión.

d) El Decreto Supremo N609/1998/Ministerio de Obras Públicas (D.O. 20 de julio de 1998) que establece Norma de emisión para la regulación de contaminantes asociados a las descargas de residuos industriales líquidos a sistemas de aicantarillado.

Esta norma de emisión inició su tramitación con su formalización en el Primer Programa Priorizado de Dictación de Normas Ambientales para 1996/1997 aprobado por la CONAMA. Igualmente, su tramitación conllevó más de dos años desde que se le incluyó en el Programa Priorizado de Normas. Sin embargo, al poco tiempo de su salida a la luz, se detectó en la norma aprobada una serie de incorrecciones que debían de subsanarse indefectiblemente, por lo que, a propuesta del Departamento de Descontaminación, Planes y Normas de CONAMA se incluyó en el Programa Priorizado de Normas para 1999/2000 la Revisión de la "Norma De Emisión Para La Regulación De Contaminantes Asociados A Las Descargas De Residuos Industriales Liquidos A Sistemas De Alcantarillado", establecida en el D.S. 609/98, del 7 de mayo de 1998, del Ministerio de Obras Públicas. Lo que constituye un buen ejemplo, aunque excepcional a la luz de la práctica sobre esta materia que aquí se examina, de la aplicación del procedimiento de aprobación de normas de emisión establecido sobre el mismo patrón que el procedimiento aplicable a la promulgación de normas de calidad ambiental. Esta decisión supuso que la revisión de la norma de emisión primigenia fuese sometida al procedimiento de aprobación de normas en todas sus etapas y lo que finalmente, ha culminado con la promulgación de un nueva norma de emisión mediante el D.S. No3.592/2000/Ministerio de Obras Públicas (D.O. 29 de septiembre de 2000) que modifica el Decreto Supremo ${ }^{\circ} 609$ de 7 de Mayo de 1998, de Obras Públicas, que establece Norma de Emisión para la Regulación de Contaminantes Asociados a Descargas de Residuos Industriales Líquidos a Sistemas de Alcantarillado. Este es un ejemplo del sometimiento al procedimiento 
en forma rigurosa, para modificar una norma recientemente elaborada y promulgada.

e) Proyecto de Norma para el Manejo de lodos no peligrosos provenientes de plantas de tratamiento de residuos líquidos, que inició su procedimiento de aprobación el 4 de marzo de 1299, a iniciativa del Ministerio de Salud. ${ }^{9}$

Este proyecto de norma constituye un ejemplo curioso, por cuanto la norma de lodos de plantas de tratamiento NO ES una norma de calidad ni tampoco de emisión, y de ello se da expresa cuenta en la Tabla Pública elaborada el 6 de mayo de 2002 por la CONAMA, a fin de informar sobre el estado de avance de las normas ambientales que se encuentran en trámite. En esta Tabla se anota que esta norma tiene un carácter técnico, pero que para su aprobación se seguirá el procedimiento de aprobación de normas ambientales. ${ }^{10}$ Como se ha apuntado, la iniciativa de incluir esta norma en el programa priorizado de normas que lleva adelante la CONAMA procede del Ministerio de Salud, el cual, de esta forma, ha transferido la responsabilidad de la coordinación de la elaboración de la norma técnica de manejo de lodos, a la Comisión. Esta actuación del Ministerio de Salud revela que el procedimiento aprobado para la dictación de normas ambientales es un ítem interesante a seguir en el caso de elaboración de normas técnicas, por cuanto garantiza que su elaboración se realizará a la luz de antecedentes técnicos, científicos y sociales, y con un acucioso estudio de los mismos, los que serán determinantes para la aprobación de la norma. Sin embargo, esta actuación razonable del Ministerio de Salud, no se condice con su proceder en otras materias, como es el caso del D.S. N0594/1999/Ministerio de Salud, caso que se analizará con mayor detalle más adelante en la letra f), y cuya singularidad es que contiene disposiciones que reúnen la condición de normas de calidad ambiental de carácter primario y que, pese a ello, se aprobó como norma sectorial sin adoptar el procedimiento de aprobación o revisión de normas ambientales tantas veces aludido.

f) El Decreto Supremo No594 de 1999, del Ministerio de Salud (D.O. 29/04/2000), Reglamenta las Condiciones Sanitarias y Ambientales Básicas en los Lugares de Trabajo.

Este Decreto sustituye el Reglamento sobre Condiciones Sanitarias y Ambientales Básicas en los Lugares de Trabajo, aprobado por Decreto Supremo No745 de 1992, del Ministerio de Salud.

9 El estado actial del procedimiento de dictación de esta norma, es que se encuentra listo el Proyecto definitivo para ser presentado al Consejo de Directivo de la CONAMA, quedando pendiente las gestiones de aprobación del proyecto definitivo por dicho Consejo y su posterior sención mediante Decreto Supremo pot parte del Presidente de la República.

10 Vid. página web de la CONAMA al 9 de julio de 2002: http://www.conama.cl/nuestra_institucion/ areas_de_trabajos/u_planes_norma/tabia_publica_noma2.htm 
Gran parte de las vicisitudes que tuvo para entrar en vigencia el Decreto No594/1999/Ministerio de Salud, se pueden explicar si se toma en cuenta que al momento de su promulgación, tuvo una gran oposición de la Sociedad de Fomento Fabril y la Sociedad Nacional de Agricultura. Esta situación provocó la modificación del artículo 119 del Reglamento, que en la práctica cambió la fecha de entrada en vigencia inicialmente fijada para el 28 de julio de 2000, por el 30 de abril de $2001^{11}$.

Básicamente, el Decreto Supremo No594/1999/Ministerio de Salud contiene una serie de medidas obligatorias que deberán acondicionarse en los lugares de trabajo con el objeto de impedir daños tanto a los operarios como al medio ambiente. Estos daños al medio ambiente son los que podrían ocasionarse por el uso de elementos químicos, estableciendo normas especiales para la disposición de residuos sólidos o líquidos que resulten de los procesos industriales. Igualmente, contiene disposiciones relativas a la protección de los trabajadores en materia de seguridad y sanidad, como son las referentes al equipo de protección personal, las medidas para prevenir incendios, tipo de instalación de inodoros, dotación de guardarropías y comedores, etc.

Como se ha señalado, este Decreto busca no sólo ordenar medidas de seguridad y de sanidad en el trabajo, sino que también tiene por objetivo proteger a los trabajadores en cuanto personas humanas que no pueden estar expuestas a una serie de condiciones extremas que podrían atentar a su salud, así preceptúa desde el tiempo en que un trabajador puede exponerse a temperaturas bajas, los niveles máximos de ruido, así como los "limites permisibles de exposición ambiental a agentes quimicos y agentes fisicos, y aquellos limites de tolerancia biológica para trabajadores expuestos a riesgo ocupacional" (artículo 2, inciso 2), o como lo señala el artículo 55 estableciendo aquellos "agentes quimicos y fisicos capaces de provocar efectos adversos en el trabajador" (artículo 55), definiendo para estos efectos (artículo 59) una serie de conceptos que nos remiten a las normas primarias de calidad ambiental, estos son:

a) Limite Permisible Ponderado: Valor máximo permitido para el promedio ponderado de las concentraciones ambientales de contaminantes quimicos existente en los lugares de trabajo durante la jornada normal de 8 horas diarias, con un total de 48 horas semanales.

b) Limite Permisible Temporal: Valor máximo permitido para el promedio ponderado de las concentraciones ambientales de contaminantes quimicos en los lugares de trabajo, medidas en un periodo de 15 minutos continuos dentro de la jornada de trabajo. Este limite no podrá ser excedido en ningún momento de la jornada.

11 Por Decreto Supremo No556/2.000/Ministerio de Salud (D.O. 28/07/2000), se modifica el articulo 119 del Título Final del Decreto Supremo No594 de 1999, del Ministerio de Salud, sustituyéndose la expresión "90 dias" por "365 dias", con el ójjeto de conceder un plazo mayor a las empresas para que puedan realizar los acondicionamientos necesarios para dar cumplimiento con las nuevas exigencias que impone a estas entidades el Reglamento sobre Condiciones Sanitarias y Ambientales Básicas en los Lugares de Trabajo. 
c) Limite Permisible Absoluto: Valor máximo permitido para las concentraciones ambientales de contaminantes medidas en cualquier momento de la jornada de trabajo.

De este modo, concordantemente con las definiciones anteriores se establecen:

1. Los límites permisibles absolutos de las concentraciones ambientales de las sustancias capaces de causar rápidamente efectos narcóticos, cáusticos o tóxicos, de carácter grave o fatal (artículo 61);

2. Los límites permisibles ponderados y temporales para las concentraciones ambientales de las sustancias indicadas en el artículo 66;

3. Los niveles de presión sonora al que pueden exponerse temporal o permanentemente los trabajadores (artículo 75); y

4. Los niveles de exposición a vibraciones a que pueden estar sujetos los trabajadores (artículo 83 y siguientes).

Estas disposiciones que se han puntualizado responden, en nuestra opinión, a la definición de norma primaria de calidad ambiental, que como ya se anotó, son aquellas que definen los valores de las concentraciones y periodos máximos o minimos permisibles de elementos, compuestos, sustancias, derivados, quimicos o biológicos, energias, radiaciones, vibraciones, ruidos o combinación de ellos, cuya presencia o carencia en el ambiente pueda constituir un riesgo para la vida o la salud de la población (artículo 2, letra n) de la L.B.M.A.).

Este Decreto tiene un ámbito de aplicación nacional, ya que sus condiciones deberán respetarse en todo lugar de trabajo de la República.

Este Decreto refleja que, no obstante las disposiciones contenidas en la L.B.M.A., en esta materia el Ministerio de Salud aún mantiene el ejercicio de sus competencias sin tener en cuenta los procedimientos especiales establecidos por la L.B.M.A..

El Decreto Supremo No594/1999/Ministerio de Salud, presenta problemas de falta parcial de competencia, porque debía ser el Ministerio Secretaría General de la Presidencia el que haya coordinado su promulgación en estrecha colaboración con el Ministerio de Salud, y más aún, también se puede observar que padece un defecto de validez, a consecuencia de la prescindencia del procedimiento prescrito por la L.B.M.A. relativo a las normas de calidad ambiental, el cual no se tuvo en cuenta para la aprobación de una serie de disposiciones que constituyen, como se ha evidenciado en las líneas precedentes, verdaderas N.C.A. y por ende, el Decreto que se analiza padece de 
vicio de nulidad de derecho público, ${ }^{12}$ tal como está configurada por el artículo 7 de la Constitución Política del Estado. ${ }^{13}$

Para la reclamación de los Decretos Supremos que contienen normas primarias y secundarias de calidad ambiental y normas de emisión, entre otros, se establece un procedimiento de reclamo en el párrafo $7^{\circ}$ del Título II de la L.B.M.A., en su artículo $50 . .^{14}$

En estos casos, cualquier persona que considere que no se ajustan a la ley, y a la que su cumplimiento le cause perjuicio, puede recurrir al juez de letras, en un plazo máximo de 30 días contado desde la fecha de publicación en el Diario Oficial del Decreto recurrido o desde la fecha de su aplicación, tratándose de las regulaciones especiales para casos de emergencia. Este es un punto en el que se puede percibir la debilidad del sistema de protección del ciudadano frente a la actuación ilegal de la Administración, expresada en el ejercicio de su potestad reglamentaria, la que goza de una mayor protección que el propio legislador parlamentario. Sin tomar en cuenta, la reforzada presunción de legalidad que le proporciona la toma de razón, por parte de la Contraloría General de la República.

Esta mayor protección del legislador reglamentario se basa en que el plazo para recutrir por ilegalidad, como es en este caso, contra los Reglamentos aprobados por Decreto Supremo son extremadamente cortos, computándose desde la fecha de su publicación en el Diario Oficial. No es difícil reconocer que los probablemente afecta-

12 No es menestet en este trabajo abundar en los argumentos que configutan la nulidad de derecho público. Para ello nos remitimos a los vaiiosos estudios de: Reyes Riveros, J., La nulidad de derecho público, Editorial Conosur, 2a Edición, 2000; Soto Kloss, E., "La Nulidad de Derecho Público en el Derecho Chileno", en Revista de Derecho Público, No $47-48$ diciembre 1990, Facultad de Derecho, Universidad de Chile, pp. 1I -25; y de esre mismo autor "La invalidación de los actos administrativas en el Derecho chileno", en Revista de Derecho y Jurisprudencia, Tomo LXXXV, $1^{2}$ parte, 1998, pp. 175-167.

13 El artículo 7 de la Constitución Políica preceptúa como dos de los requisitos de esencial importancia para la validez de la actuación de los entes públicos, la competencia y el procedimiento o forma establecida por la ley, sancionando al acto que no los reúna, con la nulidad de derecho público y el surgimiento de eventuales responsabilidades y sanciones. De este modo, textualmente este artículo establece:

"Los ónganos del Estado actúan válidamente previa investidura regular de sus integrantes, dentro de su competencia y en la forma que prescriba la ley.

Ninguna magistratura, ninguna persona ni grupo de personas pueden atribuirse, ni aun a pretexto de circunstancias extraordinarias, otra autoridad o derechos que los que expresamente se les hayan conferido en virtud de la Constitución $o$ las leyes.

Todo acto en contravención a este articulo es nulo y originará las responsabilidades y sanciones que la ley señale."

14 El artículo 50 de la L.B.M.A. refiriéndose a las normas primarias y secundarias de calidad ambiental y las normas de emisión, aquellos que declaren zonas del terrirorio como latentes o saturadas, los que establezcan planes de prevención o de descontaminación, a la letra dispone:

"Estos decretos serán reclamables ante el juez de letras competente, de acuerdo con lo dispuesto en los articulos $60 y$ siguientes, por cualquier persona que considere que no se ajustan a esta ly y a la cual causen perjuicio. El plazo para interponer el reclamo será de treinta dias, contado desde la fecha de publicación del decreto en el Diario Oficialo desde la fecha de su aplicación, tratándose de las regulaciones especiales para casos de emergencia. La interposición del reclamo no suspenderá, en caso alguno, los efectos del acto impugnado." 
dos por la aplicación de estas normas no se hallen en la disyuntiva de reaccionar sino cuando se les aplique concretamente la norma, y no cuando ésta se publique.

Por otra parte, la vía de la acción de nulidad de derecho público, de naturaleza ordinaria y por ende de lata tramitación, no constituye un mecanismo de protección eficaz contra los actos ilegales de la Administración. Esta situación atenta contra la vigencia efectiva del Estado de Derecho, el cual debe contar con instrumentos que permitan ajusticiar al poder público de forma oportuna y así, garantizar la observancia del principio de legalidad por parte de éste.

Ello, nos trae a plantear nuevamente lo necesario que es, respetando el principio de unidad jurisdiccional, el establecimiento de una vía especial contencioso-administrativa que permita un control pleno de la actuación administrativa, que provea a los ciudadanos no sólo de remedios contra el poder sino también de mecanismos de protección del poder frente a impugnaciones infundadas o triviales. El cuestionamiento de las decisiones de los poderes públicos deberá estar sujeto, en efecto, a un procedimiento judicial especial, que no es el general del contencioso entre sujetos privados o con relación a situaciones jurídicas ordinarias.

Por último, no se puede dejar de plantear la vía del recurso de protección a efectos de evitar daños patrimoniales derivados de la afectación del derecho de propiedad del afectado, por la aplicación de las exigencias establecidas en el cuestionado Decreto Supremo No594/1999/Ministerio de Salud, que Reglamenta las Condiciones Sanitarias y Ambientales Básicas en los Lugares de Trabajo.

g) La Resolución 505/2000/Ministerio de Transporte y Telecomunicaciones-Subsecretaria de Telecomunicaciones. ${ }^{15}$

Esta resolución fija Norma Técnica sobre Requisitos de Seguridad Aplicables a las Instalaciones de Servicios de Telecomunicaciones que generan ondas electromagnéticas. Ahora bien, bajo el supuesto de una norma de seguridad, la Subsecretaría de Telecomunicaciones, lo que en realidad ha hecho, es aprobar una norma de emisión de ondas electromagnéticas fijando un límite de exposición permanente, a público en general, procedente de una fuente particular de contaminación electromagnética como son las antenas correspondientes al Servicio Público de Telefonía Móvil. ${ }^{16}$

15 Este ejemplo también ha sido advertido por el equipo de investigadores del Centro de Estudios de Derecho Ambiental de la Facuitad de Derecho de la Ĺniversidad de Chile, quienes lo han evidenciado en las jornadas de Derecho Ambiental de noviembre de 2001.

16 El artículo tercero de la Resolución preceptúa: "Las antenas correspondientes al Servicio Público de Telefonia Móvil deberín instalarse de menera tal que, la densidad de potencia medida en los puntos a los cwales tengan libre acceso las personas en general, sea inferior a 435 micro Watts $/ \mathrm{cm}^{2}$." 
Esta norma técnica de la SUBTEL regula la emisión de cierta forma de energía, bajo condiciones objetivamente mensurables y con el fin de proteger a las personas de un riesgo potencial para la salud o calidad de vida. En ese sentido, si se comparan estos elementos con las disposiciones de la Ley de Bases Generales del Medio Ambiente, en lo relativo a la definición de norma de emisión (aquella que "establece la cantidad máxima permitida para un contaminante, medida en el efluente de la fuente emisora") puede concluirse que, bajo la apariencia del establecimiento de requisitos de seguridad para las antenas de telecomunicaciones, la Resolución 505, de 2000, de la SUBTEL, fija una norma de emisión.

En consecuencia, la norma aprobada padece de los mismos vicios de falta de competencia y de prescindencia del procedimiento que ya hemos observado en el caso del DS 594/2000/Ministerio de Salud. Con lo cual, se evade el procedimiento único y objetivo de aprobación de estas normas, cuya administración y gestión se radicó en la CONAMA.

En síntesis, la aplicación práctica del procedimiento de aprobación de las normas ambientales aquí expuesta en los diferentes ejemplos normativos, la podemos consignar en el siguiente cuadro resumen:

\begin{tabular}{|c|l|c|l|}
\hline NORMA & \multicolumn{1}{|c|}{ TEMA } & $\begin{array}{c}\text { ORGANISMO/ } \\
\text { PROCEDIMIENTO }\end{array}$ & \multicolumn{1}{|c|}{ SIGUE } \\
\hline DS 146/1997 & $\begin{array}{l}\text { Establece norma de emisión de } \\
\text { ruidos. }\end{array}$ & Ministerio de Salud. & $\begin{array}{l}\text { Sl.Norma que estaba } \\
\text { bajo la tutela del Min. } \\
\text { de Salud, su } \\
\text { claboración pasa a ser } \\
\text { coordinada por } \\
\text { CONAMA. }\end{array}$ \\
\hline DS 477/1994 & $\begin{array}{l}\text { Establece norma primaria de } \\
\text { calidad de aire para arsénico. } \\
\text { Esta norma fue derogada } \\
\text { pocos meses después por } \\
\text { DS.1.364/1994/Ministerio de } \\
\text { Salud por no sujetarse al } \\
\text { procedimiento. } \\
\text { DS 59/1998 }\end{array}$ & Ministerio de Salud. & $\begin{array}{l}\text { NO. Ejemplo de } \\
\text { Norma que es } \\
\text { Establece la norma de calidad por no } \\
\text { primaria para material } \\
\text { seguir el } \\
\text { particulado respirabie MP10. } \\
\text { procedimiento, y } \\
\text { posteriormente fue } \\
\text { re-elaborada. }\end{array}$ \\
& MINSEGPRES. & $\begin{array}{l}\text { Su aprobación Sf } \\
\text { siguí el } \\
\text { procedimiento, pero su } \\
\text { modificación NO. }\end{array}$ \\
\hline
\end{tabular}




\begin{tabular}{|c|c|c|c|}
\hline NORMA & TEMA & $\begin{array}{c}\text { ORGANISMOI } \\
\text { PROCEDIMIENTO }\end{array}$ & SIGUE \\
\hline DS $609 / 1998$ & $\begin{array}{l}\text { Establece norma de emisión } \\
\text { para la regulación de } \\
\text { contaminantes asociados a las } \\
\text { descargas de residuos } \\
\text { industriales liquidos a sistemas } \\
\text { de alcantariliado. }\end{array}$ & $\begin{array}{l}\text { Ministerio de Obras } \\
\text { Públicas. }\end{array}$ & $\begin{array}{l}\text { Se aprobó y se } \\
\text { modificó siguiendo el } \\
\text { procedimiento. }\end{array}$ \\
\hline $\begin{array}{l}\text { Proyecto de } \\
\text { Noma }\end{array}$ & Manejo de Lodos no peligrosos. & Ministerio de Salud. & $\begin{array}{l}\text { No es norma } \\
\text { ambiental, sin } \\
\text { embargo, se somete al } \\
\text { procedimiento. }\end{array}$ \\
\hline DS 594/1999 & $\begin{array}{l}\text { Reglamenta condiciones } \\
\text { sanitarias ambientales básicas } \\
\text { en los lugares de trabajo. }\end{array}$ & Ministerio de Salud. & $\begin{array}{l}\text { Contiene entre sus } \\
\text { disposiciones normas } \\
\text { de calidad primaria y } \\
\text { normas de emisión, } \\
\text { pero NO ha seguido el } \\
\text { procedimiento para la } \\
\text { aprobación de estas } \\
\text { normas. }\end{array}$ \\
\hline R. No505/2000 & $\begin{array}{l}\text { Fija norma técnica sobre } \\
\text { requisitos de seguridad } \\
\text { aplicables a las instalaciones de } \\
\text { servicios de Telecomunicaciones } \\
\text { que generan ondas } \\
\text { eiectromagnéticas. }\end{array}$ & $\begin{array}{l}\text { Subsecretaría de } \\
\text { Telecomunicaciones. } \\
\text { Ministerio de } \\
\text { Transportes y } \\
\text { Telecomunicaciones. }\end{array}$ & $\begin{array}{l}\text { Contiene norma } \\
\text { de emisión de ondas } \\
\text { electromagnéticas, } \\
\text { pero no siguió el } \\
\text { procedimiento. }\end{array}$ \\
\hline
\end{tabular}

\section{Conclusiones.}

A la luz del análisis arriba expuesto se pueden esbozar las siguientes conclusiones de la problemática abordada:

$1^{\circ}$ La vigencia de los instrumentos de Gestión Ambiental relativos a las Normas de Calidad Ambiental establecidos en la Ley de Bases de Medio Ambiente No19.300, no es plena en la práctica.

$2^{\circ}$ El procedimiento establecido por el Decreto Supremo No93/1995/Ministerio Secretaría General de la Presidencia, ha tenido una aplicación errática de acuerdo con los ejemplos presentados. En algunos casos, se ha utilizado su adopción para retardar la normación de estándares máximos de elementos "confictivos"; en otros, se ha aplicado dicho procedimiento bajo la coordinación de la CONAMA, pero a su vez se ha procedido a modificar las normas de calidad ambiental obviando la disposición legal que obliga a aplicar el mismo procedimiento cuando éstas se revisen. 
$3^{\circ} \mathrm{El}$ obviar el procedimiento de aprobación de las normas ambientales constituye una vulneración de una garantía esencial para asegurar el cumplimiento del principio de legalidad, por parte de la Administración Pública.

$4^{\circ} \mathrm{La}$ actuación de los "organismos del estado con competencia ambiental" hace patente que en la práctica no se entiende, y quizá no se ha reflexionado, sobre los alcances de la L.B.M.A.. Peor aún, la imagen de los Ministros en este tema se ve afectada por cuanto ellos son los que formalizan este actuar errático y, que se configura por las razones expuestas, en un accionar antijurídico de la Administración. Los Ministros forman parte del Consejo Directivo de la CONAMA y son los que finalmente aprueban los programas priorizados de dictación de normas y les dan la última aprobación una vez que éstas han cumplido el procedimiento, de modo que quedan listas para su promulgación por el Presidente de la República.

$5^{\circ}$ Una medida acertada para reconducir los casos que se han expuesto, y que se han aprobado prescindiendo del procedimiento, es la de incorporar dichas normas en el programa priorizado de normas ambientales que coordina y gestiona la CONAMA. Ello permitiría revalorizar este mecanismo diseñado por el legislador en la L.B.M.A., cuya mayor virtud es la de otorgar amplias garantías para su formulación y discusión y, además, sentaría un valioso precedente de ordenamiento administrativo, necesario en las metas de modernización y eficiencia de la organización administrativa.

$6^{\circ}$ En los casos descritos relativos al Decreto Supremo No45/2.001/Ministerio Secretaría General de la Presidencia, que modifica el Decreto No59/ 1998 sobre Material Particulado Respirable MP10, y el Decreto Supremo No594/1999/Ministerio de Salud, que reglamenta las Condiciones Sanitarias y Ambientales Básicas en los Lugares de Trabajo, y la R. No 505/2000/Subsec. Telecomunicaciones, que fija norma técnica sobre requisitos de seguridad aplicables a las instalaciones de servicios de Telecomunicaciones que generan ondas electromagnéticas, la prescindencia del procedimiento establecido por el Decreto Supremo No93/1995/ Ministerio Secretaría General de la Presidencia los vicia en su origen, configurándose una nulidad de derecho público conforme a lo dispuesto por el artículo 7 de la Constitución Política del Estado.

$7^{\circ}$ Los ejemplos aquí analizados delatan una falla en la aplicación de principios vitales para la eficacia y eficiencia de la Administración en el cumplimiento de sus fines; estos son el de unidad de acción y de coordinación de la actuación administrativa, los que en materia ambiental son particularmente importantes para la eficacia de la protección del dere- 
cho a vivir en un medio ambiente libre de contaminación que todos los ciudadanos tenemos.

$8^{\circ}$ Las situaciones aquí descritas denotan la ausencia de un eficaz control del ejercicio de la potestad reglamentaria de la Administración, debido a que, en los casos mencionados, la Contraloría no observó los decretos o resoluciones en cuanto a si se trataban de normas de calidad o de emisión (nuevas o modificaciones), que requerían su sometimiento al procedimiento de tramitación señalado en el D.S. 93/1995/MSGP como condición necesaria para garantizar su legalidad. Esto es particularmente grave debido a que la toma de razón por parte de la Contraloría proporciona a los reglamentos de la Administración una presunción de legalidad reforzada, y los plazos para recurrir en la váa judicial, aplicando un procedimiento sumario, cuando existen, son sumamente breves.

9० Urge, para garantizar la vigencia plena del Estado de Derecho, contar con vías eficaces de tutela judicial sobre la actuación (normativa y no normativa) de la Administración. Para ello sería conveniente el establecimiento, dentro del marco del principio de unidad jurisdiccional, de una vía especial contencioso-administrativa, que otorgue protección tanto a los derechos $\mathrm{e}$ intereses afectados de los ciudadanos, como al poder público cuestionado, frente a pretensiones infundadas. 